\title{
Therapeutic Intervention and Parenting Style of Abusive Parents
}

\author{
Fariba Arabgol $^{1, *}$; Mitra Hakim-Shooshtari $^{2}$; Lili Panaghi ${ }^{3}$ \\ ${ }_{1}^{1}$ Behavioral Science Research Center, Department of Psychiatry, Imam Hossein Hospital, Shahid Beheshti University of Medical Sciences, Tehran, IR Iran \\ ${ }^{2}$ Department of Psychiatry, Iran University of Medical Sciences, Tehran, IR Iran \\ ${ }^{3}$ Family Research Center, Shahid-Beheshti University, Tehran, IR Iran \\ ${ }^{*}$ Corresponding author: Fariba Arabgol, Behavioral Science Research Center, Department of Psychiatry, Imam Hossein Hospital, Shahid Beheshti University of Medical Sciences, \\ Tehran, IR Iran. Tel: +98-2177551023, Fax:+98-2177551023, E-mail: farabgol@sbmu.ac.irbahargol1388@yahoo.com
}

Received: July 20, 2014; Revised: August 18, 2014; Accepted: August 27, 2014

\begin{abstract}
Background: Victims of abuse comprise a significant proportion of all child psychiatric admissions, with an estimated 30\% incidence of lifetime of physical and sexual abuse among child and adolescent outpatients, and as high as $55 \%$ among psychiatric inpatients.

Objectives: The present study was conducted to examine the effects of therapeutic intervention and parent management training on parenting skill of abusive parents.

Patients and Methods: The study population consisted of all children who were referred to Child Psychiatric and Pediatric Departments of Imam Hossein Hospital, Tehran, IR Iran diagnosed with child abuse. Children and their families were visited by a psychiatrist for psychiatric problems. Later, the necessary interventions were taken for the children. To study the effect of intervention, parents completed 'Being a Parent and Parenting Scale' before intervention, and then again, in the third and sixth months following the intervention. The interventions included 8 weekly parent management training sessions for all of the involved parents and additional pharmacologic and psychological interventions according to the subjects' needs.

Results: Participants included 73 children with the mean age of $6.9 \pm 4.3$ year, while the mean age of parents was $31.76 \pm 6.52$ year for the mothers and $38.07 \pm 8.45$ year for the fathers. General anxiety disorder (30.1\%) and depression (27.4\%) were the most common psychiatric disorders among mothers. In parenting scale, there were significant differences between the zero and third month in all subscales $(P=$ 0.008 ), but there was no significant difference in verbosity and overreactivity after 6 months. Laxness showed significant changes over the period $(\mathrm{P}=0.03)$. In viewing the 'Being a Parent Scale', there was no significant difference in satisfaction and competency subscales before and after the intervention.

Conclusions: Therapeutic intervention and parent management training improves parenting skill of abusive parents, and this might lead to fewer incidents of abuse or neglect.
\end{abstract}

Keywords: Child Abuse; Intervention Studies; Parenting; Parent-Child Relations

\section{Background}

Approximately, 3000000 cases of child maltreatment are reported each year, and about one-third of them are substantiated. Victims of abuse comprise a significant proportion of all child psychiatric admissions, with an estimated $30 \%$ incidence in lifetime physical and sexual abuse among child and adolescent outpatients, and as high as 55\% among psychiatric inpatients (1).

Many abused children experience chronic symptoms of psychopathology (2). Children who have been abused or neglected are at greater risk of developing cognitive, emotional, social, and behavioral problems, which may worsen as the child grows from infancy into adulthood (3-5). A history of child abuse has been associated with future psychiatric disturbances (6), depressive disorder, and more life problems in adulthood (7). Childhood history of physical abuse is associated with an increase in depression, anxiety, anger, physical symptoms, and also medical problems (8).

Abusing parents use punitive and destructive methods, which result in more behavioral problems in their children (9). They have fewer positive interactions with their children (10) and often lack the necessary parenting skills that originate from their childhood experiences (11). Poor parenting has some biological impacts on the child; therefore, some interventions are needed to improve the quality of parent-child relationships in many situations, and it might lessen the biological effects of poor parenting (12).

Several interventions have been applied for abused children and their parents. Some interventions have focused on children while some programs have focused on the abusing parents through cognitive behavioral treatment (13). Also, family-centered studies have been used to decrease child abuse by attempting to raise parental knowledge about anger management, parenting skills, changing beliefs, and stress reduction (14-16). These methods include cognitive behavioral treatment focused on child abuse (17), modifying child-mother interactions

Copyright (C2014,Zahedan University of Medical Sciences; Published by Kowsar. This is an open-access article distributed under the terms of the Creative Commons Attribution-NonCommercial 4.0 International License (http://creativecommons.org/licenses/by-nc/4.0/) which permits copy and redistribute the material just in noncommercial usages, provided the original work is properly cited. 
(18), combining cognitive behavioral treatment for parent and child (15), and positive parenting methods (19).

Many interventions are used for abusive parents. Almost all parenting programs are designed to help parents develop more appropriate expectations of their children, to learn how to be empathetic and nurturing parents, and to use positive discipline instead of physical punishment (20). Parent training programs (PTPs) aim to change parenting practices to promote children's psychosocial development (21). Reviews and meta-analyses support the efficacy of PTP on improving parenting skills and children's behavior (22-24). Literature review suggesting that PTPs are associated with improvement in parents' behavior (13, 25-28). Researchers in the field of child abuse and neglect agree that PTPs are also relevant in a protection care context. Indeed, skills targeted by such programs reduce the risk of abuse or neglect $(27,29)$.

The positive parenting method of Sanders is one of the most common types of applied intervention programs. This method is based on a social learning model and can be effective and feasible in children with maladaptive behaviors (30). It is not only recognized as the most useful method for children with misbehavior and conduct problems (19), but also has been effective in decreasing child abuse between members of a family (31).

Parent management training has positive impacts on both parents and children. The effect on children has been assessed in another article, and this study focuses on the parents. We conducted this study to evaluate the effectiveness of therapeutic intervention and parent management training on improving parenting skills of abusive parents.

\section{Objectives}

The present study was conducted to examine the effects of therapeutic intervention and parent management training on parenting skills of abusive parents.

\section{Patients and Methods}

This study is quasi-experimental and conducted at the clinic of Child and Adolescent Psychiatry of Imam Hossein Hospital affiliated with Shahid Beheshti Medical University in Tehran, Iran. To participate, parents and children must comply with all requirements of the study by giving written informed consents after reading the procedures and purposes of the study. It was given under procedures approved by the hospital's Institutional Review Board.

\subsection{Subjects}

The study group included children and their parents who had been referred to the Emergency Room and Pediatric and Child Psychiatric Clinics of Imam Hossein Hospital from October 2008 to March 2009 diagnosed with child abuse. Participants' age ranged from infancy to 18 years old. The intervention phase lasted 3 months, but participants were followed for 6 months. The subjects were evaluated at the beginning, and then at the third and sixth month (up to 3 months after ending the intervention).

\subsection{Design and Procedures}

The participants were found through a child abuse questionnaire or from discovering signs of abuse during examination of the child by a pediatrician or psychiatrist. Next, they were introduced to the coordinator of the project. The parents were required to fill a consent form at this stage. Demographic data were collected through a questionnaire and then the children and their parents were referred to the psychiatrist for assessment. The psychiatrist assessed the children by DSM-IV-TR (diagnostic and statistical manual of mental disorder, fourth editiontext revision) criteria and K-SADS (Kiddie-schedule for affective disorders and schizophrenia), and the parents using DSM criteria and SADS. Child rearing styles were obtained by administering 'Being a Parent' (32) and 'Parenting' scale (33) which have been used in some researches in IR Iran (34).

Parents and children were visited by a child psychiatrist regularly, and therapeutic interventions (prescription drugs and psychotherapy) were done based on their individual needs and psychiatric disorder. All the parents participated in the designed project intervention package. This package consisted of 8 weekly sessions. Each session lasted 90 minutes with 8-10 participants. The first session was psycho-education about child abuse, including definition of child abuse, its kinds, negative consequences of abuse, and physical punishment as a non-effective method for children's misbehavior. The second session included anger management skills. The remaining 6 sessions revolved around parent management training and were explained according to level 4 Triple P (31). Topics of sessions included positive parenting, causes of children's misbehavior and monitoring of children's behavior (one session), positive relationship with children and encouraging desirable behavior(one session); introducing rules, giving instruction (one session), managing misbehavior by ignoring, logical, appropriate consequences and time out (two sessions), and managing high-risk situations (one session). The sessions were managed by a trained psychologist and supervised by a child psychiatrist during the project.

The parents were assessed using parenting style questionnaires (Being a Parent and Parenting scale) at the first meeting (before intervention), and then at 3 and 6 months later.

The questionnaire of 'Being a Parent' measures feelings of satisfaction and competency with regard to parenthood with 16 items (32). The 'Parenting scale' evaluates parental reaction towards misbehaviors of children. It has 30 items. Each item has a Likert score from 1 to 7; a low score shows appropriate parenting, and a high score indicates inadequate parenting. This 
scale is based on the following three factors: laxness, overreactivity and verbosity. Some items do not refer to any of these factors $(33,35)$.

\subsection{Statistical Analysis}

To analyze the data, descriptive statistics were used, including mean, standard deviation, and percentage. Repeated measures analysis of variance (ANOVA) was conducted for the comparison of scale scores at first (zero point time), third month and sixth month.

\section{Results}

A total of 73 abused children, 30 (41\%) girls and 43 (59\%) boys with the mean age of $6.9 \pm 4.3$ y were studied. Fiftyfour $(74 \%)$ children experienced physical abuse, 53 (72.6\%) children suffered from emotional abuse, 29 (39.7\%) children experienced neglect, and 3 (4.1\%) children experienced sexual abuse (Table 1). Attention deficit hyperactivity disorder was the most common psychiatric disorder (65.8\%) among abused children according to K-SADS and psychiatric interview. Eighty percent of the abused children suffered from a psychiatric disorder and $74 \%$ of them had at least two psychiatric disorders.

Mean age of parents was $31.76 \pm 6.52$ year for the mothers and $38.07 \pm 8.45$ year for the fathers. About $13.6 \%$ of mothers and $10.3 \%$ of fathers had a university education, and other parents were less educated. Moreover, $16.7 \%$ of the mothers and $92.4 \%$ of the fathers had a job. General anxiety disorder and depression were the most common psychiatric disorders in mothers based on SADS and DSM criteria with the prevalence of $22(30.1 \%)$ and $20(27.4 \%)$, respectively. Mothers in $16.7 \%$ of the subjects, fathers in $28.3 \%$, and both parents in $53.3 \%$ were the abusers (Table 1).

The detailed results of psychiatric diagnosis in children and their parents and other intervention results will come in a separate paper.

Table 2 shows parenting styles regarding both applied scales (Being a Parent and Parenting Scale) before the intervention. Low scores in the 'Parenting Scale' show appropriate parenting and high scores are a result of inadequate parenting. Verbosity has the highest mean score $(47.58 \pm 7.00)$ compared with two other subscales of the 'Parenting Scale' before the intervention.

In subscales of 'being a Parent' mean score of satisfaction was $29.89 \pm 7.29$ and competency was $27.91 \pm 6.10$ before the intervention. Repeated measure ANOVA was used for the comparison of two scales at first (zero point time), third and sixth month (Table 3) after the intervention.

In parenting scale, There were significant differences between zero and third month in all subscales $(\mathrm{P}=0.008)$. There were no significant differences in verbosity $(\mathrm{P}=$ $0.06)$ and overreactivity $(\mathrm{P}=0.16)$ after exerting intervention (6 months); however, changes in verbosity subscale is a trend. Subscale of laxness showed significant changes over these time points $(\mathrm{P}=0.03)$.
With regard to 'Being a Parent' scale, there was no significant difference in satisfaction $(\mathrm{P}=0.18)$ and competency $(\mathrm{P}=0.16)$ and total score $(\mathrm{P}=0.7)$ while comparing with repeated measure ANOVA before and after the intervention (Table 4).

Table 1. Demographic Data of Subjects ${ }^{\text {a }}$

\begin{tabular}{lc}
\hline & Statistic \\
\hline Number of children & 73 \\
Sex & \\
Male & $43(58.9)$ \\
Female & $30(41.1)$
\end{tabular}

\section{Type of child abuse}

$\begin{array}{lc}\text { Physical abuse } & 54(74) \\ \text { Emotional abuse } & 53(72.6) \\ \text { Neglect } & 29(39.7) \\ \text { Sexual abuse } & 3(4.1)\end{array}$

\begin{tabular}{|lc|}
\hline Abusive person & $10(16.7)$ \\
\hline Mother & $17(28.3)$ \\
\hline Father & $32(53.3)$ \\
\hline Both & $1(1.7)$ \\
\hline Others & Statistic: Mean \pm SD \\
\hline Mean age of parents & $31.76 \pm 6.52$ \\
\hline Mother & $38.07 \pm 8.45$ \\
\hline Father & $6.9 \pm 4.3$ \\
\hline Mean age of children
\end{tabular}

${ }^{\mathrm{a}}$ Data are presented as No. (\%) or Mean \pm SD.

Table 2. Parenting Style Scores Based on Being a Parent and Parenting Scale ${ }^{a}$

\begin{tabular}{|c|c|c|c|c|}
\hline & Number & Minimum & Maximum & Results \\
\hline \multicolumn{5}{|l|}{ Being a parent } \\
\hline Total score & 55 & 30.00 & 85.00 & $57.65 \pm 10.53$ \\
\hline Satisfaction & 55 & 16.00 & 52.00 & $29.89 \pm 7.29$ \\
\hline Competency & 56 & 12.00 & 37.00 & $27.91 \pm 6.10$ \\
\hline \multicolumn{5}{|l|}{ Parenting scale } \\
\hline Verbosity & 58 & 31.00 & 66.00 & $47.58 \pm 7.00$ \\
\hline Over reactivity & 58 & 24.00 & 64.00 & $44.22 \pm 9.79$ \\
\hline Laxness & 58 & 26.00 & 61.00 & $38.58 \pm 8.21$ \\
\hline
\end{tabular}

\footnotetext{
${ }^{\mathrm{a}}$ Data are presented as Mean $\pm \mathrm{SD}$.
} 


\begin{tabular}{|c|c|c|c|c|}
\hline & Results & $\mathrm{df}$ & $\mathrm{F}$ & P Value \\
\hline Verbosity & & 2.20 & 3.09 & 0.06 \\
\hline Before intervention & $47.58 \pm 7.00$ & & & \\
\hline 3 months after Intervention & $43.91 \pm 5.97$ & & & \\
\hline 6 months after Intervention & $49.11 \pm 6.58$ & & & \\
\hline Over reactivity & & 2.20 & 2.26 & 0.16 \\
\hline Before intervention & $44.22 \pm 9.79$ & & & \\
\hline 3 months after intervention & $37.29 \pm 11.84$ & & & \\
\hline 6 months after intervention & $49.81 \pm 19.05$ & & & \\
\hline Laxness & & 2.20 & 3.85 & 0.03 \\
\hline Before intervention & $38.58 \pm 8.21$ & & & \\
\hline 3 months after intervention & $36.63 \pm 6.30$ & & & \\
\hline 6 months after intervention & $38.29 \pm 8.94$ & & & \\
\hline
\end{tabular}

${ }^{\mathrm{a}}$ Data are presented as Mean \pm SD.

Table 4. Repeated Measure ANOVA in Subscales of Being a Parent Scale ${ }^{\text {a }}$

\begin{tabular}{|c|c|c|c|c|}
\hline & Results & $\mathrm{df}$ & $\mathrm{F}$ & P Value \\
\hline Satisfaction & & 2.26 & 1.80 & 0.18 \\
\hline Before intervention & $29.89 \pm 7.29$ & & & \\
\hline 3 months after intervention & $33.16 \pm 7.29$ & & & \\
\hline 6 months after intervention & $31.14 \pm 6.61$ & & & \\
\hline Competency & & 2.22 & 2.26 & 0.16 \\
\hline Before intervention & $27.91 \pm 6.10$ & & & \\
\hline 3 months after intervention & $28.91 \pm 5.33$ & & & \\
\hline 6 months after intervention & $29.35 \pm 5.18$ & & & \\
\hline Total & & 2.22 & 0.34 & 0.7 \\
\hline Before intervention & $57.65 \pm 10.53$ & & & \\
\hline 3 months after intervention & $61.79 \pm 11.52$ & & & \\
\hline 6 months after intervention & $60.25 \pm 9.96$ & & & \\
\hline
\end{tabular}

${ }^{\mathrm{a}}$ Data are presented as Mean $\pm \mathrm{SD}$.

Figure 1. The Changes of Scores of Parenting Subscales in Perpetrating Parents

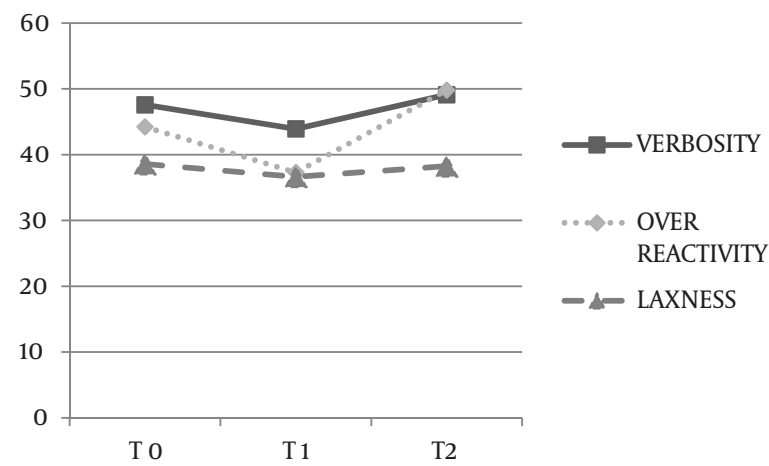

T0, before intervention; T1: 3 months after intervention; T2, 6 months after intervention.
Figure 2. The Changes of Scores of Being a Parent Subscales in Perpetrating Parents

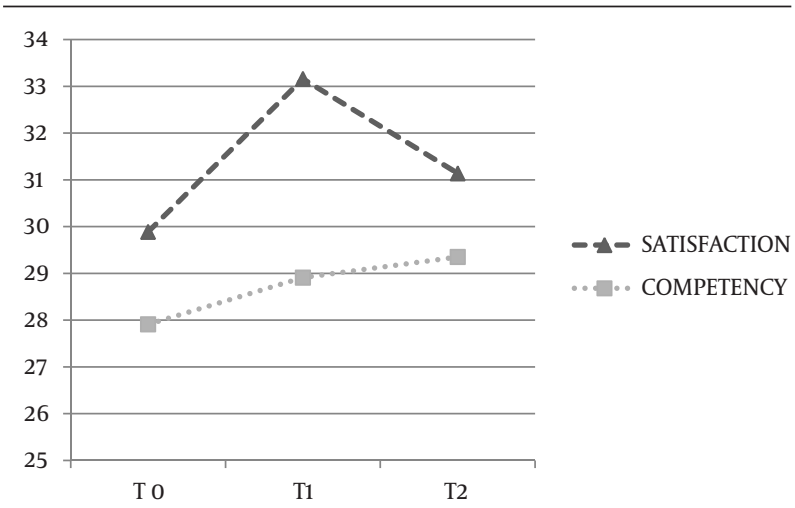

To, before intervention; T1, 3 months after intervention; T2, 6 month after intervention 


\section{Discussion}

This study evaluated the influence of therapeutic intervention and parent management training on improvement of parenting skills of abusive parents. Of subscales of parenting scale, laxness showed significant changes over the study period. Improvement in laxness can be due to education sessions, which emphasized on the importance of having clear, simple, and consistent rules. On the other hand, it appears that environment influences on laxness more than verbosity and over reactivity.

The existence of significant differences between the zero and third month evaluations in all subscales that have not continued up to the sixth months shows that abusive parents need longer intervention or booster sessions to keep the positive effects. Previous studies also mentioned relapse after initial improvement pursuant to parenting interventions and emphasized that studies are needed to see whether, some months after initial treatment, booster sessions should routinely be offered to prevent relapse (12).

On the other hand, $80 \%$ of children in our study had at least one psychiatric disorder that makes the parenting more difficult. In fact, child behavioral problems have some negative influences on the parent's ability to undertake care giving tasks (36). It seems that appropriate interventions for reducing child's misbehaviors reduce the burden of care for parents (37) and make them stronger in the parenting role and subsequently decrease the risk of inept discipline and child abuse.

Letarte et al. (21) showed more improvement than our study in parenting skills using the 'Parenting Practice Interview', although they found no difference on the measure of parenting self-efficacy feeling.

There are some differences between our study and the Letarte et al. (21) study. They assessed the effectiveness of a parent training program 'Incredible Years' in improving parenting practices with longer time, and we used positive parenting program with two extra sessions and shorter intervention phase. We do not know whether or not our results would change if we extended our session. Although in both studies, the questionnaires assessed parenting skills, they were different. Other things that may explain the differences in results may be due to the source of the samples. Our samples were recruited from a psychiatric department and almost 30\% of the mothers suffered from general anxiety disorder and depression, and although some parents in our study took other psychopharmacological interventions according to their psychiatric disease, there were no mental illness symptoms in Letarte et al. (21) samples. It may be one of the reasons that parent management training did not induce more improvement in parenting skills in our study. Previous studies also have shown that maternal depression has negative impact on parenting and is associated with the development of behavior problems in children; subsequently, this makes parenting more difficult (38).

However, the results of the present study do not show any effect of the program on the 'Being a Parent' scale or satisfaction and competency. It seems that these items originate from attitude and change in attitude requires longer time, so there was not any significant change in satisfaction and competency after 3 or 6 months.

Also previous studies mentioned that many families failed to improve with initial treatment following parenting interventions, indicating perhaps the necessity of systematic procedures to address the difficulties of these families (12). Also, in the Letarte et al. (21) study, there was no difference in the measure of parenting self-efficacy feeling. They believed that more time may be required before change could be observed in these outcomes, especially among parents who had a history of difficult parent-child interaction. Parents may be expected to develop confidence in their parenting skills over time, as they experience more successful interactions with their child (21). Results of this study support the idea that preventive-intervention programs, such as parent training, can reduce harsh disciplines in parents.

The effect of our intervention on child abuse, neglect and child misbehaviors was assessed in another article (39), but our findings in the present study show some degree of improvement in parenting skills following parent management training, and that improvement in parenting practices might lead to fewer situations of abuse or neglect $(27,29)$.

The duration of intervention and follow-up was short in our study. If we had a longer time with booster sessions, we could find the most effective factors in parenting improvement and decreasing child abuse. It is recommended that future study would address resilience indicators and how to promote resiliency in Iranian families with child abuse.

\section{Acknowledgements}

We would like to thank all the participants for their cooperation.

\section{Authors' Contributions}

Fariba Arabgol has conducted the design, execution and management of the project, writing and final approval of the manuscript; Leili Panaghi has analyzed and interpreted the data and also has cooperated for writing the result section of the manuscript; Mitra Shooshtary has contributed for writing, interpreting and final approval of the manuscript.

\section{Funding/Support}

The study was funded by Ministry of Health and Medical Education, Mental Health Office and Vice Chancellor for Research affiliated to Shahid Beheshti University of Medical Sciences, Tehran, IR Iran.

\section{References}

1. Kaufman J. Child abuse and neglect. In: Martin A, Volkmar FR editors. Lewis's Child and Adolescent Psychiatry: A Comprehensive Textbook.: Lippincott Williams and Wilkins; 2007. pp. 692-701. 
2. Boney-McCoy S, Finkelhor D. Psychosocial sequelae of violent victimization in a national youth sample. J Consult Clin Psychol. 1995;63(5):726-36.

3. Cicchetti D, Rogosch FA. The toll of child maltreatment on the developing child: Insights from developmental psychopathology. Child Adolesc Psychiatr Clin N Am.1994.

4. Hildyard KL, Wolfe DA. Child neglect: developmental issues and outcomes. Child Abuse Negl. 2002;26(6-7):679-95.

5. Lau AS, Weisz JR. Reported maltreatment among clinic-referred children: Implications for presenting problems, treatment attrition, and long-term outcomes. J Am Acad Child Adolesc Psychiatry. 2003;42(11):1327-34.

6. Ackerman PT, Newton JEO, McPherson WB, Jones JG, Dykman RA. Prevalence of post traumatic stress disorder and other psychiatric diagnoses in three groups of abused children (sexual, physical, and both). Child Abuse Negl.1998;22(8):759-74.

7. Becker-Lausen E, Sanders B, Chinsky JM. Mediation of abusive childhood experiences: depression, dissociation, and negative life outcomes. Am J Orthopsychiatry. 1995;65(4):560-73.

8. Springer KW, Sheridan J, Kuo D, Carnes M. Long-term physical and mental health consequences of childhood physical abuse: results from a large population-based sample of men and women. Child Abuse Negl. 2007;31(5):517-30.

9. Black DA, Heyman RE, Smith Slep AM. Risk factors for child physical abuse. Aggress Violent Behav. 2001;6(2):121-88.

10. Dore MM, Lee JM. The role of parent training with abusive and neglectful parents. Family Relations. 1999:313-25.

11. Egan KJ. Stress management and child management with abusive parents. JClin Child Adolesc Psychol.1983;12(3):292-9.

12. Scott S. Parenting quality and children's mental health: biological mechanisms and psychological interventions. Curr Opin Psychiatry. 2012;25(4):301-6.

13. Wolfe DA, Wekerle C. Treatment strategies for child physical abuse and neglect: A critical progress report. Clin Psychol Rev. 1993;13(6):473-500.

14. Cerezo M, D'Ocon A. Sequential analyses in coercive motherchild interaction: The predictability hypothesis in abusive versus nonabusive dyads. Child Abuse Negl. 1999;23(2):99-113.

15. Runyon MK, Deblinger E, Schroeder CM. Pilot evaluation of outcomes of combined parent-child cognitive-behavioral group therapy for families at risk for child physical abuse. Cogn Behav Pract. 2009;16(1):101-18.

16. Kolko DJ, Hoagwood KE, Springgate B. Treatment research for children and youth exposed to traumatic events: moving beyond efficacy to amp up public health impact. Gen Hosp Psychiatry. 2010;32(5):465-76.

17. Kolko DJ. Individual cognitive behavioral treatment and family therapy for physically abused children and their offending parents: A comparison of clinical outcomes. Child Maltreat. 1996;1(4):322-42.

18. Chaffin M, Silovsky JF, Funderburk B, Valle LA, Brestan EV, Balachova T, et al. Parent-child interaction therapy with physically abusive parents: efficacy for reducing future abuse reports. $J$ Consult Clin Psychol. 2004;72(3):500.

19. Sanders MR. Triple P-Positive Parenting Program: Towards an empirically validated multilevel parenting and family support strategy for the prevention of behavior and emotional problems in children. Clin Child Fam Psychol Rev.1999;2(2):71-90.

20. Barth RP. Preventing child abuse and neglect with parent training: evidence and opportunities. Future Child. 2009;19(2):95-118.
21. Letarte MJ, Normandeau S, Allard J. Effectiveness of a parent training program "Incredible Years" in a child protection service. Child Abuse Negl. 2010;34(4):253-61.

22. Lundahl B, Risser HJ, Lovejoy MC. A meta-analysis of parent training: moderators and follow-up effects. Clin Psychol Rev. 2006;26(1):86-104.

23. Serketich WJ, Dumas JE. The effectiveness of behavioral parent training to modify antisocial behavior in children: A meta-analysis. Behav Ther.1996;27(2):171-86.

24. Webster-Stratton C, Reid MJ. Treatment and prevention of conduct problems: Parent training interventions for young children (2-7 years old). In: McCartney K, Phillips D editors. Handbook of Early Childhood Development.. USA: Blackwell Publishing Ltd; 2006. pp. 616-42.

25. Barth RP, Landsverk J, Chamberlain P, Reid JB, Rolls JA, Hurlburt MS, et al. Parent-training programs in child welfare services: Planning for a more evidence-based approach to serving biological parents. Res Soc Work Pract. 2005;15(5):353-71.

26. Corcoran J. Family interventions with child physical abuse and neglect: A critical review. Child Youth Serv Rev. 2000;22(7):563-91.

27. Herbert M. Parenting skills interventions. In: Letarte MJ, Normandeau S, Allard J editors. Family matters : interfaces between child and adult mental health.. England: Routledge; 2000.

28. Lundahl BW, Nimer J, Parsons B. Preventing child abuse: A meta-analysis of parent training programs. Res Soc Work Pract. 2006;16(3):251-62.

29. Gershater-Molko RM, Lutzker JR, Sherman JA. Intervention in child neglect: An applied behavioral perspective. Aggress Violent Behav. 2002;7(2):103-24.

30. McKee TE, Harvey E, Danforth JS, Ulaszek WR, Friedman JL. The relation between parental coping styles and parent-child interactions before and after treatment for children with ADHD and oppositional behavior.J Clin Child Adolesc Psychol.2004;33(1):158-68.

31. Sanders MR, Pidgeon AM, Gravestock F, Connors MD, Brown S, Young RW. Does parental attributional retraining and anger management enhance the effects of the Triple P-Positive Parenting Program with parents at risk of child maltreatment? Behav Ther. 2004;35(3):513-35.

32. Johnston C, Mash EJ. A measure of parenting satisfaction and efficacy. J Clin Child Psychol.1989;18(2):167-75.

33. Arnold DS, O'Leary SG, Wolff LS, Acker MM. The Parenting Scale: a measure of dysfunctional parenting in discipline situations. Psychol Assess. 1993;5(2):137.

34. Tehrani-Doost M, Shahrivar Z, Mahmoudi Gharaie J, AlaghbandRad J. Efficacy of positive parenting on improving children's behavior problems and parenting styles. IJPCP. 2009;14(4):371-9.

35. Turner KMT, Dadds CM, Sanders MR. Facilitator's manual for group.Milton Australia:Triple P International; 2002.

36. Aghebati A, Gharraee B, Hakim Shoshtari M, Gohari MR. Triple ppositive parenting program for mothers of ADHD children. Iran $J$ Psychiatry Behav Sci. 2014;8(1):59-65.

37. Plant KM, Sanders MR. Reducing problem behavior during caregiving in families of preschool-aged children with developmental disabilities. Res Dev Disabil. 2007;28(4):362-85.

38. Hoffman C, Crnic KA, Baker JK. Maternal depression and parenting: Implications for children's emergent emotion regulation and behavioral functioning. Parent Sci Pract. 2006;6(4):271-95.

39. Arabgol F, Derakhshanpour F, Panaghi L, Sarjami S, Hajebi A. Effect of therapeutic intervention on behavioral problems of abused children. IJPCP. 2014;19(3):202-10. 